and by time since diagnosis ( $\leq 2$ vs. $>2$ years) for secukinumab 300 and $150 \mathrm{mg}$ is presented in the figure.

Conclusions: In the overall population, a higher proportion of pts treated with secukinumab at Wk 16 achieved DAPSA REM than those treated with placebo, with REM and LDA sustaining through Wk 104. At Wk 16, a higher proportion of anti-TNF-naïve pts treated with secukinumab achieved and sustained DAPSA REM than anti-TNF-IR pts and a higher proportion of pts with early diagnosis ( $\leq 2$ years) achieved DAPSA REM vs. pts diagnosed later ( $>2$ years).

References:

[1] Schoels MM, et al. Ann Rheum Dis 2016;75:811-8.

[2] Mclnnes IB, et al. Arthritis Rheumatol 2016;68 (suppl 10).

[3] Mclnnes, et al. Lancet 2015;386:1137-46.

Disclosure of Interest: J. Smolen Grant/research support from: AbbVie, Janssen, Eli Lilly, MSD, Pfizer, Roche, Amgen, AstraZeneca, Astro, Celgene, Celltrion, GSK, ILTOO, Medimmune, Novartis-Sandoz, Pfizer, Samsung, Sanofi and UCB., Consultant for: AbbVie, Janssen, Eli Lilly, MSD, Pfizer, Roche, Amgen, AstraZeneca, Astro, Celgene, Celltrion, GSK, ILTOO, Medimmune, Novartis-Sandoz, Pfizer, Samsung, Sanofi and UCB., I. Mclnnes Grant/research support from: AbbVie, Amgen, BMS, Celgene, Janssen, Lilly, Novartis, Pfizer, and UCB., Consultant for: AbbVie, Amgen, BMS, Celgene, Janssen, Lilly, Novartis, Pfizer, and UCB., Speakers bureau: AbbVie, Amgen, BMS, Celgene, Janssen, Lilly, Novartis, Pfizer, and UCB., T. Kvien Consultant for: AbbVie, Biogen, BMS, Boehringer Ingelheim, Celltrion, Eli Lilly, Epirus, Janssen, Merck-Serono, MSD, Mundipharma, Novartis, Oktal, Orion Pharma, Hospira/Pfizer, Roche, Sandoz and UCB., Speakers bureau: AbbVie, Biogen, BMS, Boehringer Ingelheim, Celltrion, Eli Lilly, Epirus, Janssen, Merck-Serono, MSD, Mundipharma, Novartis, Oktal, Orion Pharma, Hospira/Pfizer, Roche, Sandoz and UCB., L. Pricop Shareholder of: Novartis, Employee of: Novartis, T. Fox Shareholder of: Novartis, Employee of: Novartis, L. Rasouliyan Consultant for: Novartis through employment at RTI, Employee of: RTI Health Solutions, S. Jugl Shareholder of: Novartis, Employee of: Novartis, C. Gaillez Shareholder of: Novartis and BMS, Employee of: Novartis DOI: 10.1136/annrheumdis-2017-eular.4666

\section{AB0767 IL-17-22-23 PATHWAYS IN PSORIATIC ARTHRITIS AND PSORIASIS}

K. Nas ${ }^{1}$, R. Cevik ${ }^{2}$, I. Yildiz ${ }^{3}$, J. Rech ${ }^{4}$, G. Schett ${ }^{4} .{ }^{1}$ Division of Rheumatology and Immunology, Department of Physical Medicine and Rehabilitation, Sakarya University, Faculty of Medicine, Sakarya; ${ }^{2}$ Division of Rheumatology, Department of Physical Medicine and Rehabilitation; ${ }^{3}$ Department of Biostatistic, Dicle University, Faculty of Medicine, Diyarbakir, Turkey; ${ }^{4}$ Department of Internal Medicine and Institute for Clinical Immunology, University of Erlangen-Nuremberg, Erlangen, Germany

Background: Psoriatic arthritis (PsA) is an immune-mediated chronic inflammatory arthropathy-associated with psoriasis. T helper 17 pathway has been shown to play an important role in PsA.

Objectives: In this study, we aimed to investigate concentrations of $\mathrm{TH} 17$ pathway cytokines such as IL-17, IL-22 and IL-23 in psoriasis (PsO) with/and without structural bone damage and psoriatic arthritis ( $P s A)$, and their relationship with disease activity and clinical findings.

Methods: A total number of 74 patients, 24 patients with PsA (mean age $57.5 \pm 11.37$; 13 women, 11 men) and 25 patients with $\mathrm{PsO}$ and structural bone damage (mean age $49 \pm 13.92$; 11 women, 14 men) and 25 patients with $\mathrm{PsO}$ and no structural bone damage (mean age $41 \pm 16.77 ; 7$ women, 18 men), were recruited from the Department Internal Medicine 3 of the University of Erlangen-Numberg. Both PsO and PsA patients were evaluated according to the CASPAR criteria. Demographic and disease specific variables were recorded. Bone architecture of the metacarpal heads II and III were assessed by highresolution peripheral quantitative computed tomography (HR-pQCT, XtremeCT, Scanco, Switzerland). Disease activity was assessed with Disease Activity Score (DAS28). Psoriatic skin and nail disease activity were measured by the PASI.

Results: The ages of the patients in the three groups were similar. IL$17 A$ concentrations were significantly differed between the groups $(p=0.000)$. However, for other cytokines there was no difference between PsA and PsO groups. Serum levels of IL-17A were significantly correlated to patient pain of VAS $(r=-0.318, p=0.06)$, VAS patient global assessment $(r=0.272, p=0.021)$, DAS28 $(r=-0.394, p=0.001)$ and PASI $(r=0.519, p=0.000)$ in PSA and PSO. PASI score were also positively correlated with IL23 $(r=-0.286, p=0.015)$ and S100A8 $(r=0.298, p=0.011)$

Conclusions: IL-17A seems to play an important role in development of PsA and bone damage in $\mathrm{PsO}$. This role should be elucidated by further and larger clinical studies.

Disclosure of Interest: None declared

DOI: 10.1136/annrheumdis-2017-eular.6768

\section{AB0768 CLINICAL FEATURES OF RHEUMATOID FACTOR- OR ANTI-CYCLIC CITRULLINATED PEPTIDES-POSITIVE PATIENTS WITH PSORIATIC ARTHRITIS}

K. Inui $^{1}$, T. Okano ${ }^{1}$, H. Yoshimura ${ }^{1}$, Y. Sugioka ${ }^{2}$, K. Mamoto ${ }^{1}$, T. Koike ${ }^{2,3}$,

M. Tada ${ }^{4}$, H. Nakamura ${ }^{1}$. ${ }^{1}$ Orthopaedic Surgery; ${ }^{2}$ Center for Senile
Degenerative Disorders, Osaka City University Graduate School of Medicine, Osaka; ${ }^{3}$ Search Institute for Bone and Arthritis Disease, Shirahama Foundation for Health and Welfare, Shirahama Cho; ${ }^{4}$ Orthopaedic Surgery, Osaka City General Hospital, Osaka, Japan

Background: Although rheumatoid factor (RF) negativity is among the Classification Criteria for Psoriatic Arthritis (CASPAR) for the diagnosis of psoriatic arthritis (PsA), not all patients with PSA are seronegative. Measurement of anti-cyclic citrullinated peptides (ACPA) is another key test for rheumatoid arthritis and PsA; however, the prevalence of ACPA in patients with PsA is unclear.

Objectives: We analyzed the clinical features of RF- or ACPA-seropositive patients with PsA in comparison with seronegative patients with PsA using the ISLAND registry (UMIN000024292).

Methods: One hundred patients with psoriasis referred from dermatologists for assessment of synovitis or enthesitis from July 2015 to August 2016 were enrolled. PsA was diagnosed by CASPAR, and synovitis or enthesitis was confirmed by ultrasound assessment. Factors compared between seropositive and seronegative patients included age, sex, comorbidities, use of disease-modifying antirheumatic drugs, prevalence of enthesopathy, eye symptoms, duration between skin onset and musculoskeletal onset, psoriasis area severity index, composite psoriatic disease activity (CPDAI), psoriatic arthritis screening and evaluation (PASE), disease activity score-28 (DAS-28), and laboratory data.

Results: In total, 52 patients had PsA and 48 patients had psoriasis without any musculoskeletal manifestations. Significant differences were observed in the age at onset of psoriasis (37.4 vs. $47.9 \mathrm{y}$, respectively; $\mathrm{p}<0.01$ ) and several clinical parameters (CPDAl: 14.60 vs. 4.55 , respectively [p $<0.01$ ], PASE: 50.8 vs. 32.0 , respectively $[p<0.01]$, DAS-28: 3.77 vs. 2.72 , respectively $[p=0.009])$. ACPA positivity was observed in $15.9 \%$ of patients with PsA and in $0.0 \%$ of patients with psoriasis $(p=0.04)$. Among 44 of the 52 patients with PsA whose ACPA data were available, the duration from skin onset to joint onset was shorter in the 7 ACPA-positive patients (54.3 \pm 52.8 months) than in the 37 ACPA-negative patients (147.8 \pm 158.0 months), although the difference was not statistically significant $(p=0.30)$. There were no statistically significant differences in the PASE, DAS-28, $\mathrm{C}$-reactive protein concentration, or matrix metalloproteinase-3 concentration. The differences between RF positive and negative patients were not also statistically significant.

\begin{tabular}{|c|c|c|c|}
\hline & ACPA Positive $(n=7)$ & ACPA Negative $(n=37)$ & $p$ value \\
\hline PASE & $45.8 \pm 16.1$ & $51.1 \pm 13.4$ & 0.42 \\
\hline IBP positivity & 28.6 & 40.5 & 0.69 \\
\hline DAS28-ESR & $4.24 \pm 0.93$ & $3.76 \pm 1.56$ & 0.45 \\
\hline DAS28-CRP & $3.78 \pm 0.73$ & $3.67 \pm 1.39$ & 0.84 \\
\hline CRP (mg/dl) & $0.56[0.02-20.39]$ & $0.48[0.00-16.05]$ & 0.79 \\
\hline MMP-3 (ng/ml) & 133.6 [42.8-184.2] & $69.1[13.5-245.1]$ & 0.14 \\
\hline Duration (skin/SpA) (mo) & $54.3 \pm 52.8$ & $147.8 \pm 158.0$ & 0.26 \\
\hline
\end{tabular}

Conclusions: Among the patients with PsA in this series, ACPA positivity occurred in $15.9 \%$ and RF positivity occurred in $12.8 \%$. Seropositive patients with PsA tended to have a shorter duration between skin onset and joint onset. Clinical and laboratory findings were not significantly different between ACPA-positive and -negative patients. One possible explanation for this is that $40.4 \%$ of patients with PsA received biological disease-modifying antirheumatic drugs; therefore, their disease activity was stable.

Disclosure of Interest: None declared

DOI: 10.1136/annrheumdis-2017-eular.1898

\section{AB0769 SONOGRAPHIC SIGNS OF ENTHESITIS IN ESTABLISHED PSORIATIC ARTHRITIS AND HEALTHY VOLUNTEERS}

K. Wervers ${ }^{1}$, I. Herrings ${ }^{1}$, J.J. Luime ${ }^{1}$, M. Moed ${ }^{1}$, I. Tchetverikov ${ }^{2}$, A.H. Gerards ${ }^{3}$, J.M.W. Hazes ${ }^{1}$, M. Vis ${ }^{1}$. ${ }^{1}$ Rheumatology, Erasmus MC, Rotterdam; ${ }^{2}$ Rheumatology, Albert Schweitzer Hospital, Dordrecht; ${ }^{3}$ Rheumatology, Vlietland Hospital, Schiedam, Netherlands

Background: Previous research in our group showed that sonographic signs of enthesitis are present in early and established PsA, but in young healthy volunteers as well. The Madrid Sonographic Enthesitis Index (MASEI) was only able to differentiate between patients and healthy volunteers after excluding knee enthesis thickness from the score and semi-quantitative scoring of Power Doppler (PD) signal (1).

Objectives: We aim to validate the modified MASEI in a larger cohort of established PsA patients and healthy volunteers.

Methods: Established PsA patients and healthy volunteers aged 35-55 were asked to participate in this cross-sectional study, irrespective of presence of enthesitis complaints. The triceps, quadriceps, proximal and distal patellar and Achilles tendon and plantar fascia (i.e. the locations of the MASEI) and the common extensor insertion at the lateral epicondyle of the elbow were evaluated sonographically for structural changes (i.e. erosions, calcifications and structure) and active inflammation (thickness, bursitis and PD).

Results: 84 established PsA patients and 25 healthy volunteers participated. Sonographic structural changes and one or two spots of PD signal were common in both groups. The modified MASEl was significantly higher in PsA patients 
(median 12 (IQR 7.25-17) vs. $7.5(5-9), \mathrm{P}<0.001$ ), while the original MASEl did not differ significantly (Table 1). Confluent PD over a larger area was only seen in $8 \%$ of the established PsA patients. Structural damage on ultrasound was more pronounced in the patients compared to the healthy volunteers. Number of PD locations and PD score did not distinguish the two groups.

Table 1. Participant characteristics and sonographic enthesitis scores

\begin{tabular}{lcc}
\hline & PsA patients $(\mathrm{n}=84)$ & Healthy Volunteers $(\mathrm{n}=25)$ \\
\hline Male, $\mathrm{n}(\%)$ & $45(54)$ & $12(48)$ \\
Age, mean (SD) & $55(11)$ & $47(6)^{\star}$ \\
Disease duration, median years (IQR) & $8.0(4.9-12.3)$ & \\
LEI, median (IQR) & $0.5(0-2)$ & $0(0-0)^{\star *}$ \\
Ultrasound & & \\
MASEI, median (IQR) & $15.5(11-22)$ & $13(9-18)$ \\
Modified MASEI, median (IQR) & $12(7.25-17)$ & $7.5(5-9)^{\star \star}$ \\
structural components & $7(3-10)$ & $3(1-6)^{\star *}$ \\
inflammatory components & $6(3.5-8.5)$ & $3.5(2-5.5)$ \\
Power Doppler & $74(88)$ & \\
in any enthesis, n (\%) & $7(8 \%)$ & $22(88)$ \\
score 3, n (\%) & $2(1-3)$ & $0(0 \%)$ \\
locations, median (IQR) & $1.5(1.25-1.75)$ & $2(1-3)$ \\
if positive, median (IQR) & $1.5(1.25-1.5)$ \\
\hline
\end{tabular}

PsA: Psoriatic Arthritis; SD: standard deviation, IQR: interquartile range; LEI: Leeds Enthesitis Index; MASEI: Madrid Sonographic Enthesitis Score; modified MASEI: MASEI with new PD scoring method (1: one spot of PD, 1.5: some spots of PD, 2: confluent signal, 3: severe signal) and without knee entheses thickness. Structural components: erosions, calcifications, structure. Inflammatory components: bursitis, thickness and PD signal. PD: Power Doppler. ${ }^{*} \mathrm{P}<0.01$, ${ }^{* *} \mathrm{P}<0.001$ (Wilcoxon rank sum test).

Conclusions: Inflammatory and structural changes of the enthesis measured with ultrasound are common in both unselected PsA patients and healthy volunteers, but more pronounced in established PsA patients.

\section{References:}

[1] Wervers K, Rasappu N, Vis M, Tchetverikov I, Kok MR, Gerards AH, et al. AB0733 Masei Shows Substantial Changes in The Entheses of Young Healthy Volunteers - Amending Its PD Score and Excluding Knee Entheses Thickness Provides Better Discrimination of Enthesitis in Psoriatic Arthritis Patients. Ann Rheum Dis 2016;75:1155.

Disclosure of Interest: None declared

DOI: 10.1136/annrheumdis-2017-eular.3431

\section{AB0770 CHANGE OF PSORIATIC ARTHRITIS IMPACT OF DISEASE (PSAID12) QUESTIONNAIRE RELATED TO CHANGE IN DISEASE ACTIVITY IN EARLY PSORIATIC ARTHRITIS}

K. Wervers ${ }^{1}$, J.J. Luime ${ }^{1}$, I. Tchetverikov ${ }^{2}$, A.H. Gerards ${ }^{3}$, M.R. Kok ${ }^{4}$, C.W.Y. Appels ${ }^{5}$, W. van der Graaff ${ }^{6}$, J.H.L.M. van Groenendael ${ }^{7}$

L.-A. Korswagen ${ }^{8}$, J.J. Veris-van Dieren ${ }^{9}$, J.M.W. Hazes ${ }^{1}$, M. Vis ${ }^{1}$ on behalf of Cicero. ${ }^{1}$ Rheumatology, Erasmus MC, Rotterdam; ${ }^{2}$ Rheumatology, Albert

Schweitzer Hospital, Dordrecht; ${ }^{3}$ Rheumatology, Vlietland Hospital, Schiedam; ${ }^{4}$ Rheumatology, Maasstad Hospital, Rotterdam; ${ }^{5}$ Rheumatology, Amphia Hospital, Breda; ${ }^{6}$ Rheumatology, Rivas Hospital, Gorinchem; ${ }^{7}$ Rheumatology, Reumazorg Zuid West Nederland, Roosendaal; ${ }^{8}$ Rheumatology, Sint Franciscus Gasthuis, Rotterdam; ${ }^{9}$ Rheumatology, Reumazorg Zuid West Nederland, Goes, Netherlands

Background: The Psoriatic Arthritis Impact of Disease 12-item questionnaire (PsAID12) has been developed to measure impact of Psoriatic Arthritis (PsA) for purposes of monitoring and clinical management. Although validated in patients with longstanding disease, data on validity and sensitivity to change in early PsA is lacking.

Objectives: We aim to relate change in disease activity to change in PSAID12 score in early PsA and evaluate which PsAID domains are more likely to change. Methods: Patients with a new diagnosis of PsA were included in the Dutch southwest Early Psoriatic Arthritis cohoRt (DEPAR). For this analysis, patients that have PsAID12 (range 0-10) and Composite Psoriatic Disease Activity Index (CPDAI, range 0-15) data at two consecutive visits (i.e. 3 months apart) within the first year were included. In case multiple periods per patients were available, the first time period was chosen. The change in PsAID is compared to the change in disease activity over this period, measured with the CPDAI using Spearman's correlation coefficient. Change in score on individual domains of the PsAID was analysed in subgroups of patients that perceived improvement in health and those that perceived worsening. The SF-36 question on self-perceived change in health was used to determine these subgroups.

Results: 143 unique patients had at least one period with two PSAID and CPDAI measurements ( 67 from baseline-3 months, 26 3-6 months, 25 6- 9 months and 25 9-12 months). Mean age was 51 (SD 13.7) and 70 (49\%) were male. The initial median PsAID was 3.35 (IQR 1.4-5.1) and the subsequent score was 2.25 (0.95-4.8 with a mean delta of $0.52(\mathrm{P}<0.01)$. Median first CDPAl score was $4(2-7)$ and $3(1-5)$ for the second with a mean delta of $0.45(P<0.05)$. The difference in PSAID score was significantly but moderately correlated with the difference in CPDAI (Spearman's rho $0.267, \mathrm{P}=0.0013)$. 58 patients $(41 \%)$ report a better health status compared to 3 months ago. Figure 1 shows that patients with self-perceived improvement of health have the highest improvement in pain and only domains of skin problems and embarrassment/shame did not improve significantly. Patients reporting worsening of health $(n=29)$ only have significantly lower scores in fatigue, discomfort and social domains.

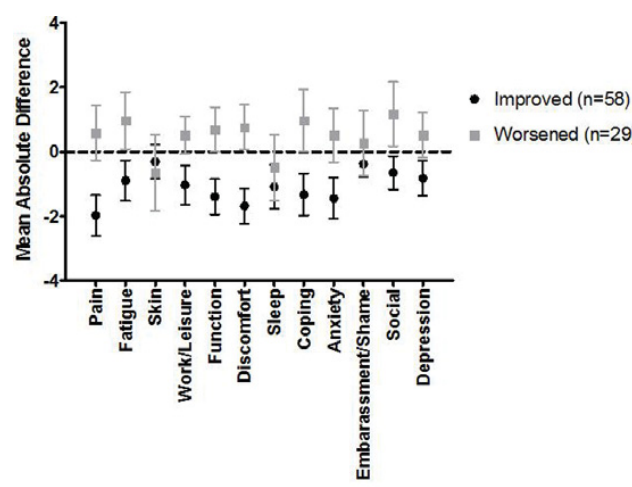

Figure 1. Mean absolute differences in PSAID12 domains in patients with self-perceived improvement of health ( $n=58$, black) and patients reporting worsening of health ( $n=29$, grey). Shown as mean value and $95 \%$-Confidence Interva

Conclusions: Improvement in CPDAI disease activity is significantly but moderately associated with improvement in PSAID score, with the biggest improvement in the pain domain in patients with a self-reported improvement of health.

Disclosure of Interest: None declared

DOI: 10.1136/annrheumdis-2017-eular.3817

\section{AB0771 SAFETY AND EFFICACY OF APREMILAST THROUGH 104 WEEKS IN PATIENTS WITH MODERATE TO SEVERE PSORIASIS WHO CONTINUED ON APREMILAST OR SWITCHED FROM ETANERCEPT TREATMENT IN THE LIBERATE STUDY}

K. Reich ${ }^{1}$, M. Goodfield ${ }^{2}$, L. Green ${ }^{3}$, K. Nograles ${ }^{4}$, R. Chen ${ }^{4}$, E. Levi ${ }^{4}$, R.G.B. Langley ${ }^{5}$. ${ }^{1}$ Dermatologikum Hamburg, Hamburg, Germany; ${ }^{2}$ Leeds General Infirmary, Leeds, United Kingdom; ${ }^{3}$ George Washington University School of Medicine, Washington, DC; ${ }^{4}$ Celgene Corporation, Summit, United States; ${ }^{5}$ Dalhousie University, Halifax, Canada

Background: Many patients (pts) with chronic plaque psoriasis exhibit nail and scalp involvement that can markedly affect quality of life and be difficult to treat. Objectives: The phase 3b LIBERATE (Evaluation in a Placebo-Controlled Study of Oral Apremilast and Etanercept in Plaque Psoriasis) study (NCT01690299) evaluated the efficacy and safety of apremilast or etanercept vs. placebo in biologic-naive pts with moderate to severe plaque psoriasis. Efficacy assessments included effects on preexisting nail and scalp disease and skin lesions.

Methods: In this double-blind, double-dummy study, pts were randomized (1:1:1) to placebo (PBO), apremilast $30 \mathrm{mg}$ BID (APR), or etanercept $50 \mathrm{mg}$ QW (ETN) through Week 16; thereafter, all pts switched to or continued APR (PBO/APR, ETN/APR, APR/APR) through Week 104. The primary end point was achievement of $a \geq 75 \%$ reduction from baseline in Psoriasis Area and Severity Index (PASI) score (PASI-75) at Week 16 with APR vs. PBO; the secondary end point was PASI-75 achievement at Week 16 with ETN vs. PBO. Physician assessments were also conducted for overall disease activity (static Physician's Global Assessment [sPGA]); scalp disease activity (Scalp Physician Global Assessment [ScPGA], limited to patients with score $\geq 3$ at baseline, indicating moderate to very severe scalp disease); and nail disease (Nail Psoriasis Severity Index [NAPSI], limited to patients with active disease [NAPSI $\geq 1$ ] in the target nail at baseline). Responses were assessed at Week 104 using the last-observation-carried-forward (LOCF) methodology.

Results: The APR extension phase (Weeks 16 to 104) included 226 pts (PBO/APR $n=73$; APR/APR $n=74$; ETN/APR $n=79$ ). At Week 16, PASI-75 scores vs. PBO were significant for both APR and ETN; long-term treatment with APR maintained both PASI-75 and SPGA 0 or 1 response levels (Table). Improvements were seen in nail and scalp disease at Week 16, and responses continued to improve with APR treatment over 104 weeks and in pts who switched from ETN to APR (Table). ScPGA 0 or 1 was achieved by $50.0 \%$ to $59.2 \%$ of pts across treatment arms, and mean percent improvement from baseline NAPSI score ranged from $-48.1 \%$ to $-51.1 \%$ (Table); the proportion of pts achieving NAPSI-50 response ranged from $48.6 \%$ to $65.2 \%$. Adverse events (AEs) occurring in $\geq 5 \%$ of pts during Weeks 0 to 16 were diarrhea, nausea, nasopharyngitis, upper respiratory tract infection, and headache; long-term assessment by exposureadjusted incidence rates (EAIR)/100 pt-yrs showed no increase with longer-term APR exposure. No increase in EAIR/100 pt-yrs of serious AEs occurred during the APR extension phase ( 3.45 to 5.49 , across groups) vs. Weeks 0 to 16 (PBO 0.0 ; ETN 7.91; APR 12.57). Changes in laboratory parameters were infrequent and transient; EAIR/100 pt-yrs remained low across groups through 104 weeks. Conclusions: APR demonstrated efficacy through Week 104 in pts who continued APR and pts who switched from PBO or ETN to APR at Week 16. The AE profile remained consistent with prolonged APR exposure, and no new safety or tolerability issues were observed through Week 104 in pts with moderate to severe plaque psoriasis. 